\title{
Virological Non-Suppression Among HIV-Positive Patients on Antiretroviral Therapy in Northwestern Nigeria: An Eleven-Year Experience of A Tertiary Care Centre, January 2009-December 2019
}

\section{Suleiman Bello Abdullahi ( $\sim$ bellonsaleehawa@gmail.com )}

Department of Family Medicine, Federal Medical Centre Katsina, Nigeria

Olayinka Ibrahim

Department of Paediatrics, Federal Medical Centre, Katsina

Abdulkadir Okeji

Department of Family Medicine, Federal Medical Centre, Lokoja, Nigeria

Yandoma lliyasu

Department of Family Medicine, Federal Medical Centre Katsina, Nigeria

Ibrahim Bashir

Department of Haematology and Blood transfusion, Federal Medical Centre, Katsina Nigeria

Suleiman Haladu

African Field Epidemiology Network (AFENET)_NFELTP, Abuja Nigeria

\section{Suleiman Idris}

African Field Epidemiology Network (AFENET)_NFELTP, Abuja Nigeria

Tijani Idris Oseni

Department of Family Medicine, Ambrose Alli University, Ekpoma, Nigeria

\section{Suleiman Muhammad}

Department of Paediatrics, Federal Medical Centre, Katsina

\section{Mohammed Yahaya}

Department of Medical Microbiology and Parasitology, Usmanu Danfodiyo University, Sokoto Nigeria

\section{Mabel Aworh}

African Field Epidemiology Network (AFENET)_NFELTP, Abuja Nigeria

Mu'awiyyah Sufiyan

Department of Community Medicine, Ahmadu Bello University Zaria, Kaduna Nigeria

\section{Research Article}

Keywords: Viral Non-suppression, HIV-Positives, Antiretroviral Therapy, Nigeria.

Posted Date: January 27th, 2021 
DOl: https://doi.org/10.21203/rs.3.rs-146794/v1

License: (c) (1) This work is licensed under a Creative Commons Attribution 4.0 International License. Read Full License 


\section{Virological Non-suppression among HIV-Positive Patients on Antiretroviral Therapy in Northwestern Nigeria: An eleven-year experience of a tertiary care Centre, January 2009_ December 2019}

*Suleiman Bello Abdullahi ${ }^{1,2}$,Olayinka Rasheed Ibrahim ${ }^{3}$, Abdulkadir Baba Okeji ${ }^{4}$, Rabilu Iliyasu Yandoma ${ }^{1}$, Ibrahim Bashir ${ }^{5}$, Suleiman Haladu ${ }^{2}$, Suleiman Ahmad Idris ${ }^{2}$, Oseni TIA ${ }^{6}$, Suleiman Bello Muhammad ${ }^{3}$, Mohammed Yahaya ${ }^{7}$, Mabel Kamweli Aworh ${ }^{2}$, Mu'awiyyah Babale Sufiyan $^{8}$.

1. Department of Family Medicine, Federal Medical Centre Katsina, Nigeria

2. African Field Epidemiology Network (AFENET)_NFELTP, Abuja Nigeria

3. Department of Paediatrics, Federal Medical Centre, Katsina Nigeria

4. Department of Family Medicine, Federal Medical Centre, Lokoja, Nigeria

5. Department of Haematology and Blood transfusion, Federal Medical Centre, Katsina Nigeria

6. Department of Family Medicine, Ambrose Alli University, Ekpoma, Nigeria

7. Department of Medical Microbiology and Parasitology, Usmanu Danfodiyo University, Sokoto Nigeria

8. Department of Community Medicine, Ahmadu Bello University Zaria, Kaduna Nigeria

* Corresponding Author: bellonsaleehawa@gmail.com ～+2348032886630 


\begin{abstract}
:
Background: Human Immuno-Deficiency Virus (HIV) remains one of the world's significant public health challenges. Viral suppression is the key indicator for treatment success in People living with HIV (PLHIV). We determined the level of viral non-suppression and its associated factors among PLHIV attending Federal Medical Centre Katsina (FMC Katsina), Nigeria.

Methods: This retrospective descriptive study was conducted on 913 HIV positive adults enrolled in care between January 2009 and December 2019. Information on socio-demographics, clinical, immunological, Viral Load (VL) and other relevant parameters were extracted from the patients' care Centre Katsina estimated frequencies/proportions, performed bivariate and multivariate analysis to determine factors associated with VL non-suppression using $\mathrm{p}<0.05$ as significant level.

Results: Records of 831 registered patients were analyzed using Epi-info 7. During the period, $751(90.4 \%)$ achieved viral suppression, 426 (51.3\%) had CD4 counts of $\geq 500$ and 477 (57.4\%) were on HAART for $\geq 5$ years. Majority, 793 (95.4\%) were on first-line and $809(97.4 \%)$ in the non-advanced stage (WHO stages 1 and 2). The independent predictors of viral non-suppression included being on the second line HAART [Adjusted OR (AOR) 6.5; 95\% CI 3.02-13.89], being employed [AOR 0.26; 95\% CI 0.15-0.44] and baseline CD4 count less than 500 [AOR 0.35; $95 \%$ CI $0.21-0.61]$.
\end{abstract}

Conclusions: Our study demonstrated a good viral suppression among PLHIV on HAART. Low baseline CD4 counts and being on second-line HAART are predictive of viral non-suppression while being unemployed seems to be protective against viral non- suppression.

Key words: Viral Non-suppression, HIV-Positives, Antiretroviral Therapy, Nigeria. 


\section{Background:}

Human Immuno-Deficiency Virus (HIV) is a leading cause of infections worldwide despite the success of highly active antiretroviral therapy (HAART) [1]. It remains one of the world's most significant public health challenges, affecting about 38 million of the world's population majority of whom are living in low and middle income countries [2]. Nigeria shares a chunk of this estimate with a recent national prevalence of $1.4 \%$. With varying prevalence across the country, Katsina state has the lowest prevalence of $0.3 \%$ while Akwa-Ibom state has the highest prevalence of $5.6 \%[3,4]$.

The 90-90-90 target by UNAIDS envisages that by 2020, 90\% of PLHIV will know their HIV status, $90 \%$ of people who know their HIV-positive status will be accessing treatment and $90 \%$ of people on treatment will have suppressed viral loads ${ }^{5}$. However, in 2018 Nigeria has only $67 \%$ of PLHIV that knew their status, of which 53\% were on treatment and only $42 \%$ were virally suppressed ${ }^{5}$. The northwest zone of Nigeria also reflects similar statistics as only 9 out of 20 PLHIV on HAART achieved viral suppression [5,6].

Viral load (VL) measurement is the gold standard for monitoring treatment success. PLHIV on HAART with unsuppressed viral load have a higher risk of disease progression, transmission, and mortality [7]. Available statistics have shown that Nigeria is far behind the target of 'UNAIDS 90-90-90 aspirations' despite the recent downward trend in prevalence and incidence. Within the limits of our literature search on major databases- PubMed, Medline, Scopus, Google scholars, and Web of Science-there was no research that has evaluated viral suppression among HIV patients in the north-western part of Nigeria. 
The objective of this study was to determine the level of viral suppression and factors associated with viral load non-suppression among HIV positive adults attending the HIV clinic at FMC Katsina.

\section{Methods:}

This retrospective cross-sectional descriptive study was conducted from January 2009 to December 2019 at FMC, Katsina. The hospital is a 1000 bed capacity, tertiary health facility. It serves as a referral center for both private and other public health facilities in the state, neighboring states, and the Niger Republic.The HIV clinic otherwise refers to as Action Aid clinic was established in 2006 and provides services for the diagnosis, treatment, and prevention of HIV, inclusive of free counseling and testing. It can accommodate about two hundred patients per clinic day and further subdivided into units. The HIV clinic units included the adult ART clinic, Paediatrics ART unit, the Prevention of Mother-to-Child Transmission (PMTCT) unit, HIV/TB co-infection unit, Pharmacy unit and the laboratory.

\section{Study participants and data collection}

The source of data was from the database of the HIV clinic obtained from all PLHIV enrolled in ART care from January 2009 to December 2019 at FMC Katsina. The database provided information on socio-demographics, clinical, immunological, virological and other relevant parameters of patients. A total number of 913 adult clients were enrolled within the study period and they were all considered as the study subjects. We excluded children and adolescents less than 18 years. We used VL testing data for samples corresponding to HIV positive patients who had been on HAART for at least 6 months. Where there were more than one VL results, the most recent (not more than 12 months in line with the country's national guideline for HIV) was used 
for the data. We abstracted data on VL testing results (for plasma and DBS) measured in terms of viral RNA copies/ml of blood.

\section{Outcome Measures}

The primary outcome was virological non-suppression, defined as having $\geq 1000$ copies of viral $\mathrm{RNA} / \mathrm{ml}$ of blood for plasma or $\geq 5000$ copies of viral RNA $/ \mathrm{ml}$ of blood for dry blood spots. The secondary outcome was factors predictive of virological non-suppression.

\section{Laboratory Testing Methods}

The laboratory analysis was carried out by the CDC accredited laboratory of the Aminu Kano Teaching Hospital, Kano. For each sample collected from the patients, RNA was extracted and plasma VL determined using Polymerase chain reaction (PCR).

\section{Data Quality Assurance}

One of the authors extracted the data into Microsoft Excel spreadsheet and this was verified independently by two other co-authors to ensure accuracy of the data.

Data analysis This was done using Epi-info version 7. to estimate the proportion of patients with virological non-suppression. Univariate analysis was used to describe the demographic characteristics and clinical indices of the patients using frequencies and proportions. Bivariate analysis was performed to identify factors associated with viral load non-suppression. Factors found to be significant at bivariate analysis were included in the unconditional logistic regression model used for multivariate analysis at a significance of $\mathrm{p}<0.05$. 


\section{Results:}

During the study period, out of 913 enrolled subjects, 831 (91.0\%) were included in the final data analysis due incomplete information in 82 clients. The ages ranged from 18 to 77 years. The mean age (standard deviation) of the subjects was $34.5 \pm 9.3$ years. Most of the subjects were below the age of 50 years $(782 ; 94.1 \%)$. There were more females, $578(69.6 \%)$. A total of 709 $(85.3 \%)$ were unemployed while $78.6 \%$ were married as shown in Table 1.

Table 1. Socio-demographic profile of the study participants $(n=831)$

\begin{tabular}{|c|c|c|}
\hline Variables & Frequency $(n)$ & Percentage (\%) \\
\hline \multicolumn{3}{|l|}{ Current Age (Years) } \\
\hline $18-27$ & 56 & 6.7 \\
\hline $28-37$ & 295 & 35.5 \\
\hline $38-47$ & 305 & 36.7 \\
\hline $48-57$ & 138 & 16.6 \\
\hline $58-67$ & 34 & 4.1 \\
\hline $68-77$ & 2 & 0.2 \\
\hline$\geq 78$ & 1 & 0.1 \\
\hline \multicolumn{3}{|l|}{ Gender } \\
\hline Male & 253 & 30.4 \\
\hline Female & 578 & 69.6 \\
\hline \multicolumn{3}{|l|}{ Occupation } \\
\hline Business & 7 & 0.8 \\
\hline Employed & 114 & 13.7 \\
\hline Retired & 1 & 0.12 \\
\hline Unemployed & 709 & 85.3 \\
\hline \multicolumn{3}{|l|}{ Marital Status } \\
\hline Divorced & 56 & 6.7 \\
\hline Married & 653 & 78.6 \\
\hline Single & 56 & 6.7 \\
\hline Widowed & 66 & 7.9 \\
\hline \multicolumn{3}{|l|}{ Educational level } \\
\hline Qur'anic & 12 & 1.4 \\
\hline Primary & 163 & 19.6 \\
\hline Secondary & 536 & 64.5 \\
\hline Tertiary & 104 & 12.5 \\
\hline None & 16 & 1.9 \\
\hline \multicolumn{3}{|l|}{ Location } \\
\hline Far $(>100 \mathrm{Km}$ from $* \mathrm{FMCK})$ & 63 & 7.6 \\
\hline Near $(<100 \mathrm{Km}$ from FMCK $)$ & 768 & 92.4 \\
\hline
\end{tabular}


Out of the 831 subjects, $751(90.4 \%)$ achieved viral suppression while $426(51.3 \%)$ had baseline CD4 counts of 500 and above. Based on the duration of the HAART, 477 (57.4\%) were on drugs for five years and more. Most of the subjects 793 (95.4\%), were on first-line HAART, and 809 (97.4\%) in the non-advanced stage of HIV (WHO stages 1 and 2). The tuberculosis status was known in $21(2.7 \%)$ of the subjects' while $11.3 \%$ were obese. Furthermore, 20 out of 578 females were pregnant $(3.5 \%)$ as shown in Table 2. 
Table 2: Clinical and Laboratory Parameters of the Study Participants ( $\mathrm{n=831}$ )

\begin{tabular}{lcc}
\hline Variables & Frequency & Percentage (\%) \\
\hline Viral Load (cp/ml) & 751 & \\
Suppressed & 80 & 90.4 \\
Unsuppressed & & 9.6 \\
Baseline CD4 (umol/L) & 404 & 48.7 \\
$<500$ & 426 & 51.3 \\
$\geq 500$ & 94 & \\
Body Mass Index $\left(\mathbf{K g} / \mathbf{m}^{\mathbf{2}}\right)$ & 737 & 11.3 \\
Obese & & 88.7 \\
Not Obese & 354 & \\
Years on HAART & 477 & 42.6 \\
$<5$ years & 793 & 57.4 \\
$\geq 5$ years & 38 & 95.4 \\
Current HAART Regimen & & 4.6 \\
First Line & 21 & 2.7 \\
Second Line & 731 & 97.3 \\
TB Status & & \\
Yes & 809 & 97.4 \\
No & 22 & 2.6 \\
Disease stage & & \\
WHO stages 1 and 2 & 560 & 96.5 \\
WHO stages 3 and 4 & 20 & 3.5 \\
Pregnancy Status (n=580) & & \\
Not Pregnant & & \\
Pregnant &
\end{tabular}


The sex, age, year of commencement of HAART, body mass index (BMI), educational status, distance from the facility, pregnancy status, and disease stages were not associated with nonviral suppression. However, CD4 count at the start of the treatment was associated with non-viral suppression (CD4 less than 500 at the start of the treatment had a higher risk of non-suppression (odds ratio [OR] of 3.3; 95\% CI 1.96-5.51). The employment status (OR 0.23, 95\% CI 0.140.38), and the HAART regimen (OR 7.30; 95\% CI 3.63-14.68) were also related to viral nonsuppression as shown in Table 3. 
Table 3: Bivariate analysis of some selected variables and Viral load status ( $\mathrm{n}=\mathbf{8 3 1}$ )

\begin{tabular}{|c|c|c|c|c|c|}
\hline \multirow[b]{2}{*}{ Variables } & \multicolumn{2}{|c|}{ Viral Load (cp/ml) } & \multirow[b]{2}{*}{ OR } & \multirow[b]{2}{*}{$95 \% \mathrm{CI}$} & \multirow[b]{2}{*}{ P-value } \\
\hline & $\begin{array}{c}\text { Suppressed } \\
(<1000)\end{array}$ & $\begin{array}{c}\text { Unsuppressed } \\
(\geq 1000)\end{array}$ & & & \\
\hline \multicolumn{6}{|l|}{ Gender } \\
\hline Male & 233 & 20 & 1.35 & $0.79-2.28$ & 0.266 \\
\hline Female & 518 & 60 & & & \\
\hline \multicolumn{6}{|l|}{$\begin{array}{l}\text { Age at Start of } \\
\text { HAART(Years) }\end{array}$} \\
\hline$<35$ & 390 & 49 & 0.68 & $0.43-1.10$ & 0.112 \\
\hline$\geq 35$ & 361 & 31 & & & \\
\hline \multicolumn{6}{|l|}{ BMI $\left(\mathrm{Kg} / \mathrm{m}^{2}\right)$} \\
\hline Not Obese & 666 & 71 & 0.99 & $0.48-2.06$ & 0.985 \\
\hline Obese & 85 & 9 & & & \\
\hline \multicolumn{6}{|l|}{ Years on ART } \\
\hline$\leq 5$ & 325 & 29 & 0.62 & $0.384-1.004$ & 0.050 \\
\hline$>5$ & 355 & 51 & & & \\
\hline \multicolumn{6}{|l|}{ CD4 at start of care } \\
\hline$<500$ & 345 & 59 & 3.3 & $1.96-5.51$ & $\leq 0.001$ \\
\hline \multirow{2}{*}{\multicolumn{6}{|c|}{ Educational status }} \\
\hline & & & & & \\
\hline Not Educated & 13 & 3 & 0.45 & $0.13-1.62$ & $0.194^{\mathrm{a}}$ \\
\hline Educated & 738 & 77 & & & \\
\hline \multicolumn{6}{|l|}{ Employment Status } \\
\hline Employed & 91 & 30 & 4.35 & $2.63-7.20$ & $\leq 0.001$ \\
\hline Not Employed & 660 & 50 & & & \\
\hline \multicolumn{6}{|l|}{$\begin{array}{l}\text { Current HAART } \\
\text { regimen }\end{array}$} \\
\hline First Line & 728 & 65 & 7.30 & $3.63-14.68$ & $<0.001$ \\
\hline Second Line & 23 & 15 & & & \\
\hline \multicolumn{6}{|l|}{ Location } \\
\hline $\begin{array}{l}\text { Far }(>100 \mathrm{Km} \text { from } \\
\text { FMCK) }\end{array}$ & 60 & 3 & 2.29 & $0.68-7.28$ & $0.263^{\mathrm{a}}$ \\
\hline $\begin{array}{l}\text { Near }(<100 \mathrm{Km} \text { from } \\
\text { FMC) }\end{array}$ & 691 & 77 & & & \\
\hline \multicolumn{6}{|l|}{ TB Status } \\
\hline Yes & 19 & 2 & 0.99 & $0.23-4.34$ & $1.000^{\mathrm{a}}$ \\
\hline No & 662 & 69 & & & \\
\hline \multicolumn{6}{|l|}{ Pregnancy Status } \\
\hline Not Pregnant & 503 & 57 & 1.56 & $0.44-5.48$ & $0.451^{\mathrm{a}}$ \\
\hline Pregnant & 17 & 3 & & & \\
\hline \multicolumn{6}{|l|}{ Disease Stage } \\
\hline WHO stages 1 and 2 & 732 & 77 & 1.50 & $0.43-5.19$ & $0.461^{\mathrm{a}}$ \\
\hline WHO stages 3 and 4 & 19 & 3 & & & \\
\hline
\end{tabular}

${ }^{\text {a }}$ Fischer's exact 
After adjusting for confounders, the independent predictors of non-viral suppression included being on the second line HAART regimen (Adjusted OR [AOR] 6.5; 95\% CI 3.02-13.89), being employed (AOR 0.26; 95\% CI 0.15-0.44) and having a baseline CD4 count greater than 500 (AOR 0.35; 95\% CI 0.21-0.61) as shown in Table 4 below.

Table 4: Logistic Regression Analysis: Predictors of Viral Non-suppression in the study subjects $(\mathbf{n}=831)$

\begin{tabular}{lccc}
\hline Variables & AOR & CI & P-value \\
\hline $\begin{array}{l}\text { Current HAART Regimen } \\
\text { Second Line }\end{array}$ & 6.5 & $3.02-13.89$ & $<0.001$ \\
$\begin{array}{l}\text { First Line } \\
\text { Years on HAART }\end{array}$ & & & \\
$\begin{array}{l}>\text { 5years } \\
\leq 5 \text { years }\end{array}$ & 1.1 & $0.62-1.79$ & 0.833 \\
$\begin{array}{l}\text { Occupational Status } \\
\text { Not Employed }\end{array}$ & 0.26 & & \\
$\begin{array}{l}\text { Employed } \\
\text { Baseline CD4 count } \\
\text { (umol/L) }\end{array}$ & & $0.15-0.44$ & $<0.001$ \\
$\geq 500$ & & & \\
$<500$ & 0.35 & & $<0.001$ \\
\hline
\end{tabular}




\section{Discussion:}

The level of non-viral suppression in this study is low and falls within the global target set of 90\% viral suppression among PLHIV on HAART by USAID [5]. This study also showed that the level of viral suppression in this cohort is one of the highest levels of viral suppression in the low-middle income country. This level of viral load suppression is higher compared with the national level of viral suppression of $44.4 \%$ in the north-western part of Nigeria [6]. The value of viral suppression in this study is also higher compared with $79 \%$ in a multi-center Nigerian study [8], and 84\% in Borno state in north-eastern Nigeria [9], 69\% in Ghana [10] and 73\% in northern Ethiopia [11]. Our findings of a high level of viral suppression are comparable with the reports from Uganda where a level viral suppression of $95 \%$ was observed after 12 months of HAART among PLHIV [12]. Similarly, the level of viral non-suppression obtained in this study is comparable to $9.0 \%$ reported in the African cohort study [13], and 7.0\% reported in Vietnam [14] after at least 12 months of HAART. The high levels of viral suppression observed in this study compared to the other studies may be due to several reasons; for instance, the cut off used for the viral suppression in our study was VL < less 1000 compared with a low value of 400 used in the earlier Nigeria study that evaluated viral suppression after test and treat protocols [8] and after six months of initiation of first-line of HAART in a Moroccan study [15]. Besides, our centre is also a tertiary health care centre with a dedicated unit for PLHIV and patients routinely undergo adherence counselling during their clinic visits which could have enhanced their compliance with their medications [16]. Our findings also suggest that the goal of achieving a $90 \%$ level of viral suppression is achievable in a resource-limited country like ours and the current approach in the management of HIV should be sustained. 
Our study also showed the factors associated with viral load non-suppression to include low baseline CD4 counts, employed people, and being on second-line HAART. The study in Ethiopia also found that low baseline CD4 count and $2^{\text {nd }}$ line HAART regimen were associated with viral load non-suppression [11]. In contrast, the study in Borno State, north-eastern Nigeria found the age group and marital status to be associated with viral load non-suppression [9]. A study in South Africa also identified low CD4 count to be associated with high viral load [17]. The CD4 cells are one of the prime targets of HIV, hence it's fall corresponds to increasing viral loads. Although not the main marker of monitoring HIV in the recent, low CD4 counts at the beginning of treatment calls for closer monitoring of the PLHIV as they have a higher chance of having viral load non-suppression.

This study showed the independent predictors of non-viral suppression among the cohorts as being on the second line HAART, with an odds ratio of six and half times compared with those on the first-line. This is consistent with the observation in Borno State, northeast Nigeria where being on the second line HAARTs was associated with viral load non-suppression [9]. The African cohort study also found that being on the second line HAART was predictive of viral load non-suppression [13]. The higher level of non-suppression of viral load in those on the second line HAART may indicate a high level of resistance as patients are moved to second-line following the failure of first-line. This is also a source of concern as non-viral suppression on second-line may necessitate consideration for the commencement of third-line HAART which are presently limited. Besides, being unemployed seems to be protective against viral load nonsuppression with odds of 0.22 . A study in Ghana that included occupations among factors that may predict non-suppression of viral load, did not observe any significant relationship [10]. Several factors may account for a higher level of non-suppression of viral load among the 
employed people in this study. The work schedules may affect their compliance and adherence levels. Also, those that work in the formal sectors may not be regular at clinic follow up due to their work schedules and the need for frequent permission for clinic attendance. Our study also showed that baseline CD4 counts greater or equal to 500 are protective against non-suppression of viral loads with odds of 0.35 . Similarly, a study in Ethiopia also observed low CD4 count to be predictive of viral load non-suppression [18]. In Vietnam, low CD4 counts were also found to be predictive of non-viral suppression [14]. The findings of low baseline CD4 counts as predictive of viral load non-suppression affirms the previous observation that patients with high viral loads tend to have low CD4 counts and suggests a slow viral clearance.

In conclusion, our study demonstrates a low level of viral non-suppression among PLHIV on HAART and the target of $90 \%$ viral suppression in the PLHIV on HAART by the USAID is achievable in the resource constraint settings. Also, having low baseline CD4 count and being on second-line HAART are predictive of viral load non-suppression, while being unemployed seems protective against non-suppression of viral load.

Limitations: The study used secondary data, hence the analysis might have missed some important variables that can significantly determine the VL status in the study participants.

\section{Abbreviations:}

AIDS: Acquired Immune Deficiency Syndrome; AOR: Adjusted Odds Ratio; ART: Antiretroviral therapy; CD-4: Cluster of Differentiation 4; CDC: Centers for Disease Control and Prevention; CI: Confidence Interval; OR: Odds Ratio; HIV: Human Immunodeficiency Virus PEPFAR: President's Emergency Plan For AIDS Relief; PLHIV: People Living With HIV/AIDS; P-value: Precession value UNAIDS: United Nations Programme on HIV and AIDS; VL: Viral Load; WHO: World Health Organization; FMC Katsina: Federal Medical Centre, Katsina. 


\section{Declarations:}

Acknowledgement: We wish to acknowledge the entire staff of HIV-Clinic, FMC Katsina and the IHVN Nigeria

Authors' contributions:

SBA conceptualized and designed the study, involved in data analyses, acquisition of data, tabulating the data, interpretation of data, preparing tables and figures, drafting the initial manuscript and critically revising the manuscript. ORI has involved in interpretation of data, drafting the initial manuscript, and critically revising the manuscript. ABO, RIY, IB, SH, SAI, OTIA, SBM, MY and MKA have contributed in interpretation of the data, initial draft synthesis, and revising the manuscript. MKA and MBS have primary responsibility for final content and involved in final review. All authors read and approved the final manuscript.

Funding: There was no fund for this study.

Availability of data and materials:

The data that support the findings of this study are available from the Federal Medical Centre, Katsina HIV clinic. Data are available from the authors upon request and with permission of Federal Medical Centre, Katsina management. Request for permission to access this data should be directed to the Medical Director, Federal Medical Centre, Katsina-Nigeria.

Ethics approval and consent to participate: Ethical clearance and approval were obtained from Federal Medical Centre, Katsina Health Research Ethics Review Committee with the registration number FMCNHREC.REG.003/082012. All methods and procedures in this study were performed in accordance with approved guidelines of the research ethics committee. Permission to use the data was obtained from the Medical Director, Federal Medical Centre Katsina. The data were from a secondary database on HIV infected patients for VL monitoring while on treatment. Informed consent was gotten from all adults enrolled in care in the HIV clinic of the Hospital that information generated in the course of their care could be used for research purposes. The data were not accessible by any other third party other than the study team.

Consent for publication: Not applicable 
Competing interests: Authors' declare that there are no competing interests.

Corresponding Author details: Federal Medical Centre, Katsina, P. M. B: 2121, Murtala Mohammed Way (Jibia Bypass), Katsina Nigeria. 


\section{REFERENCES:}

1. The Global Burden of Disease study (GBD 2015)_HIV collaborators. Estimate of global, regional, and national incidence, prevalence and mortality of HIV, 1980-2015: the global burden of disease study 2015. Lancet HIV 2016:3(8):e361-87 Available at https://doi.org/10.1016/s2352-3018(16)30087-x. [Accessed on January 22 $2^{\text {nd }}, 2020$ ]

2. World Health Organization. HIV/AIDS Fact File. Available at: https://www.who.int/news-room/fact-sheets/detail/hiv-aids. [Accessed on $1^{\text {st }}$ November, 2020]

Available at https://origins.who.int/features/factfiles/hiv/en last accessed date???

3. UNAIDS Press Release Abuja/Geneva 14 ${ }^{\text {th }}$ March 2019 Available at https://www.unaids.org/en/resources/presscentre/pressreleaseandstatentarchive/2019/m arch/20190314_nigeria. [Accessed on January $22^{\text {nd }}, 2020$ ]

4. National Agency for the Control of AIDS (NACA). Nigeria HIV Prevalence Rate. Available at https://naca.gov.ng/nigeria-prevalence-rate/. [Accessed on January 22 ${ }^{\text {nd }}$, 2020]

5. UNAIDS. The 90-90-90 Ambitious Treatment Target to Help End AIDS Epidemic. Available at http://www.unaids.org/en/resources/documents/2014/90-90-90. [Accessed on January $22^{\text {nd }}, 2020$ ]

6. National Agency for the Control of AIDS (NACA). Nigeria HIV/AIDS Indicator and Impact Survey March 2019. Available at https://naca.gov.ng/wpcontent/uploads/2019/03/NAIIS-NORTHWEST. [Accessed on January 22 ${ }^{\text {nd }}, 2020$ ]

7. World Health Organization. What's New in Treatment Monitoring: Viral Load and CD4 Testing. WHO-HIV-2017 Update July 2017. Available at: 


\section{https://apps.who.int/iris/bitstream/handle/10665/235891/WHO-HIV-2017.22-eng.}

[Accessed on January 20 2020 ].

8. Kristen A. Stafford, Solomon F. Odafe, Julia Lo, Ramat Ibrahim, Akipu Ehoche, Mercy Niyang et al. Evaluation of the clinical outcomes of the Test and Treat strategy to implement Treat All in Nigeria: Results from the Nigeria Multi-Center ART Study. Plos One.14, 1-20 (2019). https://doi.org/10.1371/journal.pone.0218555

9. Fadoju Sunkanmi, Yunana Paul, Dickson Peter, Affiah Nsikan, Jasini Joseph, Emmanuel Opada et al. Factors Influencing Viral Load Non-suppression among People Living with HIV (PLHIV) in Borno State, Nigeria: A Case of Umaru Shehu UltraModern Hospital. J. Adv. Med. Res.32, 98-105 (2020).

10. Patrick Ofori-Attah, Louis Selassie Ameke, Christian Obirikorang, Verner Ndudiri Orish, Godsway Edem Kpene, Eric Agboli et al.Viral Suppression and Its Associated Factors in HIV Patients on Highly Active Antiretroviral Therapy (HAART): A Retrospective Study in the Ho Municipality, Ghana. AIDS Res. Treat.2020, 1-7

11. Desta A. A, Tewolde W. W., Nesredin Futwi, Gebrecherkos T. G, Goyitom G. G, Asfawosen A. B, et al. HIV virological non-suppression and factors associated with non-suppression among adolescents and adults on antiretroviral therapy in northern Ethiopia: A retrospective study. BMC Infect. Dis.2020; 20:1-10

12. Deogratius Ssemwanga, Juliet Asio, Christine Watera, Maria Nannyonjo, Faridah Nassolo, Sandra Lunkuse et al. Prevalence of viral load suppression, predictors of virological failure and patterns of HIV drug resistance after 12 and 48 months on firstline antiretroviral therapy: a national cross-sectional survey in Uganda. J Antimicrob Chemother. 2020 May 1;75(5):1280-1289. doi: 10.1093/jac/dkz561 
13. Francis Kiweewa, Allahna Esber, Ezra Musingye, Domonique Reed, Trevor A. Crowell, Fatim Cham et al. HIV virologic failure and its predictors among HIV-infected adults on antiretroviral therapy in the African Cohort Study. PLoS One. 2019;14: 1-16 Available from: https://doi.org/10.1371/journal.pone.0211344 [Accessed on $1^{\text {st }}$ May, 2020]

14. Suresh Rangarajan, J Colby Donn, Le Truong Giang, Duc Duong Bui, Huu Hung Nguyen, Plui Broh Tou, et al. Factors associated with HIV viral load suppression on antiretroviral therapy in Vietnam. $J$ Virus Era. 2016 Apr 1;2(2):94-101

15. Abebe, G. \& , Zegeye Bonsa, W. K. Treatment Outcomes and Associated Factors in Tuberculosis Patients at Jimma University Medical Center: A 5-Year Retrospective Study Gemeda. Int. J. Mycobacteriology. 2017; 6:239-245

16. E.K. Mainaa, H. Mureithia, A.A. Adana, J. Muriukib, R.M. Lwembeb, E.A. Bukusi. Incidences and factors associated with viral suppression or rebound among HIV patients on combination antiretroviral therapy from three counties in Kenya. Int. J. Infect. Dis.2020; 97:151-158

17. Govender S, Otwombe K, Essien T, Panchia R, de Bruyn G, Mohapi L, et al. (2014) CD4 Counts and Viral Loads of Newly Diagnosed HIV-Infected Individuals: Implications for Treatment as Prevention. PLoS ONE 9(3): e90754. https://doi.org/10.1371/journal.pone.0090754

18. Bayu B, Tariku A, Bulti AB, Habitu YA, Derso T, Teshome DF. Determinants of virological failure among patients on highly active antiretroviral therapy in University of Gondar Referral Hospital, Northwest Ethiopia: a case-control study. HIV/AIDS - Res. 
Palliat. Care. 2017 Aug 8;9:153-159. doi: 10.2147/HIV.S139516. PMID: 28848364; PMCID: PMC5557910. 